\section{Contribution of modern cardiovascular treatment and risk factor changes to the decline in coronary heart disease mortality in Scotland between 1975 and 1994}

\author{
S Capewell, C E Morrison, J J McMurray
}

\begin{abstract}
Objective-To estimate the fall in coronary heart disease (CHD) mortality in Scotland attributable to medical and surgical treatments, and risk factor changes, between 1975 and 1994.

Design-A cohort model combining effectiveness data from meta-analyses with information on treatment uptake in all patient categories in Scotland.

Setting and patients-The whole Scottish population of 5.1 million, including all patients with recognised CHD.

Interventions-All cardiological, medical, and surgical treatments, and all risk factor changes between 1975 and 1994 . Data were obtained from epidemiological surveys, routine National Health Service sources, and local audits.
\end{abstract}

Main outcome measures-Deaths from CHD in 1975 and 1994.

Results-There were 15234 deaths from CHD in 1994, 6205 fewer deaths than expected if there had been no decline from 1975 mortality rates. In 1994, the total number of deaths prevented or postponed by all treatments and risk factor reductions was estimated at 6747 (minimum 4790, maximum 10695 ). Forty per cent of this benefit was attributed to treatments (initial treatments for acute myocardial infarction $10 \%$, treatments for hypertension $9 \%$, for secondary prevention $8 \%$, for heart failure $8 \%$, aspirin for angina $2 \%$, coronary artery bypass grafting surgery $2 \%$, and angioplasty $0.1 \%$ ). Fifty one per cent of the reduction in deaths was attributed to measurable risk factor reductions (smoking 36\%, cholesterol $6 \%$, secular fall in blood pressure $6 \%$, and changes in deprivation $3 \%$ ). Other, unquantified factors apparently accounted for the remaining $\mathbf{9 \%}$. These proportions remained relatively consistent across a wide range of assumptions and estimates in a sensitivity analysis.

Conclusions-Medical treatments and risk factor changes apparently prevented or postponed about 6750 coronary deaths in Scotland in 1994. Modest gains from individual treatments produced a large cumulative survival benefit. Reductions in major risk factors explained about half the fall in coronary mortality, emphasising the importance and future potential of prevention strategies.

(Heart 1999;81:380-386)
Keywords: mortality; coronary heart disease; treatment; risk factors

Since about 1965, coronary heart disease (CHD) mortality rates have halved in many Western countries. ${ }^{1-3}$ Explaining these remarkable falls has proven difficult. Studies in the 1980s in North America and Australasia suggested that reductions in coronary risk factors explained the greater part of the fall in mortality. Medical and surgical treatments were considered to account for only $40 \%$ of the reduction in coronary deaths. ${ }^{12}$ Recent Finnish studies concluded that up to $80 \%$ of the fall in coronary mortality was caused by favourable changes in risk factors. ${ }^{3}$ Yet many new cardiac therapies have been shown to reduce mortality, including thrombolytic therapy, aspirin, angiotensin converting enzyme (ACE) inhibitors, and statins..$^{5-10}$

More precise estimates of the mortality benefits of treatments are now available from meta-analyses. ${ }^{5-10}$ In addition, several local and national audits, notably the UK action on secondary prevention through intervention to reduce events (ASPIRE) study, have recently provided crucial data on the uptake of effective therapies in routine British practice. ${ }^{11-13}$ These important developments make a reassessment of the contribution of cardiological treatments to the continuing fall in coronary mortality particularly timely. Scotland has a well established heath service with good routine data collection. ${ }^{14}$ In addition, comprehensive cardiovascular epidemiological data have been collected in Scotland over the past three decades. ${ }^{12}{ }^{15-17}$ We have therefore examined the contribution of modern treatments to the reduction in coronary deaths in Scotland since 1975.

\section{Methods}

CALCULATION OF THE FALL IN CHD DEATHS

BETWEEN 1975 AND 1994

The number of CHD deaths expected in 1994, had there been no change in age specific mortality rates since 1975, was calculated by indirect age standardisation. The age and sex specific mortality rates for 1975 were applied to the Scottish population in 1994. The CHD deaths actually observed in 1994 were then subtracted to give the fall in CHD deaths between 1975 and 1994. 
SPECIFIC TREATMENTS EVALUATED AND THE CALCULATION OF TREATMENT EFFECTIVENESS To permit comparison with previous studies, the same basic approach was used. ${ }^{12}{ }^{18-20}$ The number of CHD deaths prevented or postponed was calculated for each specific intervention, such as coronary artery bypass grafting (CABG). This was done by applying the absolute risk reduction obtained with each relevant treatment to the appropriate patient group in Scotland for the year 1994. ${ }^{1}{ }^{2}$ 18-20

Wherever possible, the absolute mortality benefit of specific treatments was determined using systematic overviews and meta-analyses of randomised controlled trials. Otherwise, individual large randomised controlled trials were used. Survival benefit over a one year time interval was used for all treatments.

The interventions considered were as follows:

(1) Initial treatments for acute myocardial infarction: prehospital cardiopulmonary resuscitation, ${ }^{13}$ in-hospital resuscitation, aspirin, ${ }^{6}$ thrombolytic treatment, ${ }^{7}$ intravenous $\beta_{6-9}$ blockers, ${ }^{22}$ and $\mathrm{ACE}$

(2) Secondary prevention following myocardial infarction: treatment with aspirin, ${ }^{6} \beta$ blockers, ${ }^{22}$ warfarin, comprehensive rehabilitation (for which all patients are potentially eligible), ${ }^{62}$ ACE inhibitors, and HMG CoA reductase inhibitor treatment (where selected patients are eligible)..$^{8-11}$ The effects of these treatments were evaluated for all patients alive in 1994 who had been discharged from hospital after an acute myocardial infarction during the previous five years, from 1989 to 1994 . This total was adjusted for a subsequent readmission rate of $20 \%$, and an annual mortality loss of $5 \%$.

(3) Secondary prevention following angioplasty or cardiac surgery, using the same medications.

(4) Treatment of angina in hospital: aspirin, heparin, ${ }^{22}$ CABG surgery, and coronary angioplasty. ${ }^{623-25}$ Angioplasty was assumed to have a maximum mortality benefit equal to CABG surgery for one and two vessel disease and a minimum effect of zero. ${ }^{24} 25$ Because revascularisation benefit may continue for at least 10 years, all angina patients alive in 1994 following admission to hospital within the past 10 years for CABG surgery (13 384) or for angioplasty (6114) were considered. ${ }^{24}$

(5) Angina patients in the community given aspirin. ${ }^{6} \beta$ blockers were assumed to have no mortality benefit in the absence of a previous infarct. ${ }^{22}$ The prevalence of angina in Scotland is approximately $11 \%$ in both men and women aged 45-64 years and $18 \%$ in those aged 65 years or older. ${ }^{14}{ }^{16}$ This produced a total of 260982 angina subjects. To prevent double counting, this total was reduced to 156751 after adjusting for two potential overlaps: the hospital angina categories above; and the $39 \%$ of angina patients with a history of myocardial infarction (included in the sec- ondary prevention categories above). ${ }^{14} 16$ On the basis of ASPIRE and local audits, it was estimated that $33 \%$ of these patients were treated with aspirin. ${ }^{11} 14$

(6) Treatment of heart failure with ACE inhibitors. ${ }^{8}$ Patients admitted to hospital and those managed in primary care were considered. Three quarters of the 9526 patients admitted to hospital in 1994 were assumed to have severe heart failure and to obtain the mortality reduction demonstrated in the first cooperative north Scandinavian enalapril survival study (CONSENSUS I) trial. ${ }^{8}$ The remaining quarter, and patients treated in the community, were assumed to have mild to moderately severe heart failure and to obtain a smaller absolute benefit from treatment. ${ }^{8}$ Local and national audits indicated that in 1994 in Scotland some $40 \%$ of hospital patients and $20 \%$ of community patients received ACE inhibitor treatment (appendix 1). To adjust for overlap, it was assumed that half the community patients had received inpatient treatment.

(7) Treatment of hypertension, estimated as treatment of individuals. ${ }^{5}$ In 1994, the prevalence of hypertension (defined as a diastolic blood pressure $>95 \mathrm{~mm} \mathrm{Hg}$, or a systolic blood pressure $>160 \mathrm{~mm} \mathrm{Hg}$, or treatment with antihypertensive medication) was approximately $35 \%$ in men and $50 \%$ in women aged over 45 years. ${ }^{26} \mathrm{It}$ was estimated that, overall, some $62 \%$ of patients were treated, and that half of these patients complied sufficiently to achieve an effective diastolic blood pressure reduction of $6 \mathrm{~mm} \mathrm{Hg}$ or more. ${ }^{526}{ }^{27}$ Blood pressure was also analysed as a population risk factor (see below).

Patient groups considered for treatment

The numbers of individual CHD patients eligible for, and given, specific treatments were identified using a variety of sources detailed in an appendix available from the authors.

\section{Adjustment for patient overlap}

Adjustments for potential overlaps between patient groups, such as hypertension and heart failure, or angina and secondary prevention postinfarction, were made using data from the third monitoring trends and determinants in cardiovascular disease (MONICA) risk factor survey, and elsewhere, as detailed in the results section and appendix $1 .{ }^{17}$

\section{Combination therapy}

In conditions where combination therapy is common, such as acute myocardial infarction and secondary prevention, clinical trial evidence is sparse, but suggests that the same relative benefit from each treatment may operate cumulatively. ${ }^{28}$ Cumulative benefit was therefore estimated using the formula: relative benefit $=1-(1-$ treatment $a) \times(1-$ treatment b), etc. ${ }^{28}$ 
Treatment adherence (compliance)

Adherence (compliance) was defined as the proportion of patients taking therapeutically effective levels of treatment. ${ }^{26}{ }^{27}$ Overall compliance was assumed to be $100 \%$ in hospital inpatients, $70 \%$ in symptomatic patients with angina or heart failure, and $50 \%$ in patients with hypertension. A modest age gradient was assumed. ${ }^{26} 27$

IMPACT OF CHANGES IN POPULATION RISK FACTORS FOR CHD

Changes in the prevalence of measurable risk factors, including smoking, cholesterol, deprivation, and blood pressure, were obtained from recent Scottish epidemiological studies and surveys (appendix 1). The contribution of risk factor changes to the fall in coronary mortality between 1975 and 1994 was calculated as the average value obtained from using two independent methods. The first is a regression method, based on recent studies from Finland, Iceland, and elsewhere. ${ }^{3418-20} 29$ This generated a regression $\beta$ coefficient value, describing the percentage reduction in mortality to be expected for each per cent reduction in that specific risk factor. ${ }^{3}{ }^{418-20} 2930$ The mortality effect of changes in population cholesterol concentration was also calculated using a recent meta-analysis. ${ }^{30}$ The second method is the population attributable risk method, based on the local Renfrew and Paisley study. ${ }^{12151819}$ Of all CHD deaths in men, $40 \%$ were attributable to smoking, $31 \%$ to raised blood pressure, $25 \%$ to social class, and $24 \%$ to raised cholesterol $(37 \%, 39 \%, 32 \%$, and $21 \%$ in women, respectively). For each factor, this was an effect independent of all other factors. ${ }^{15}$

\section{Population blood pressure}

Between 1986 and 1995, mean population diastolic blood pressure in north Glasgow adults aged $45-64$ years fell by $6.8 \mathrm{~mm} \mathrm{Hg}$ in men, and by $6.1 \mathrm{~mm} \mathrm{Hg}$ in women (appendix 1). To extrapolate these changes to the Scottish population, the following assumptions were made: (a) that a similar fall occurred throughout Scotland; (b) that the fall in blood pressure in the period 1975 to 1986 was at least half that between 1986 and 1995; and (c) that the fall in subjects aged $>65$ years of age was at least half that in those aged 45-64 (appendix 1)..$^{1426}$

\section{Cholesterol}

Between 1985/86 and 1994/95, the mean serum cholesterol concentrations in the north Glasgow population, aged $45-64$, fell by an average of $3.3 \%$ in men and $4.9 \%$ in women (appendix 1). To extrapolate these changes to the Scottish population, the same assumptions were made as for blood pressure.

\section{Changes in socioeconomic status}

Carstair's deprivation scores were obtained based on decennial census data comprising social class, overcrowding, male unemployment, and car ownership (appendix 1). The reduction in CHD deaths caused by changes in socioeconomic deprivation were then calcu- lated on the basis of a population attributable risk of $25 \%$ in men and $32 \%$ in women. ${ }^{15}$

Other, currently unquantified risk factors

It was not possible to obtain satisfactory trend data for other potentially important risk factors such as obesity, exercise, clotting factors, "Barker" cohort effects, or dietary changes apart from cholesterol. ${ }^{14}$ A pragmatic decision was, therefore, taken to attribute any shortfall in the total model estimate to these factors.

\section{MORTALITY REDUCTION FROM TREATMENTS}

ALREADY IN USE IN 1975

A number of effective therapies were already in limited use in 1975. These included CABG, cardiopulmonary resuscitation in the community and in hospital, $\beta$ blockers (though not used systematically for secondary prophylaxis), and therapy for moderate and severe hypertension (defined as a diastolic blood pressure $>105 \mathrm{~mm} \mathrm{Hg}) .^{513212224}$ Precise patient data for some of these interventions, such as CABG, and eligible hypertensives, were available from the data sources detailed above. Others were estimated after consultation with cardiologists in practice in 1975 .

\section{STATISTICAL ANALYSES}

Mortality effects were analysed by sex and age categories. Almost all the key parameters were subject to uncertainty, with potential overestimation or underestimation of benefit. Multiway sensitivity analyses were therefore performed using the analysis of extremes method. This generates the best estimate, along with the minimum and maximum plausible values. ${ }^{31}$ These sensitivity analyses examined the effects on the mortality reduction estimates of variations in the major parameters: patient numbers, group overlap, treatment uptake, treatment compliance (concordance), and treatment effectiveness. ${ }^{12182031}$ An example is given in appendix 2 .

\section{Results}

CHD MORTALITY IN SCOTLAND IN 1975 AND 1994 There were 18251 (10 321 male) CHD deaths in Scotland in 1975 (International Classification of Diseases (ICD) codes 410-414). If the 1975 age specific mortality rates had continued unchanged, and adjusting for changes in the population age structure, 21439 deaths would have been expected in 1994. In fact, only 15234 deaths occurred in 1994, 6205 fewer deaths than expected (3690 fewer in men and 2515 in women).

EFFECTS OF MEDICAL AND SURGICAL

TREATMENTS

In each treatment category, the best, maximum, and minimum estimates of deaths prevented or postponed were calculated by multiplying the number of eligible patients by treatment uptake, treatment compliance, and absolute risk reduction per 100 patients treated (table 1, appendix 2). 
Table 1 Contribution of individual treatments to the fall in coronary heart disease mortality in Scotland, 1975 to 1994. Deaths prevented or postponed as a result of treatments

\begin{tabular}{|c|c|c|c|c|c|}
\hline Treatments & $\begin{array}{l}\text { Patients } \\
\text { eligible }\end{array}$ & $\begin{array}{l}\text { Uptake of } \\
\text { intervention }\end{array}$ & $\begin{array}{l}\text { Absolute risk } \\
\text { reduction }\end{array}$ & $\begin{array}{l}\text { Death prevented or } \\
\text { postponed }\end{array}$ & $\begin{array}{l}\text { Proportion of overall } \\
\text { deaths prevented or } \\
\text { postponed }\end{array}$ \\
\hline Acute MI & 15505 & - & 0.069 & $694(366-1083)$ & $10 \%$ \\
\hline Community CPR & 6357 & 0.5 & 0.056 & $178(168-188)$ & - \\
\hline Hospital CPR & 1355 & 0.95 & 0.150 & $193(55-271)$ & - \\
\hline Thrombolysis alone & 12181 & 0.01 & 0.030 & $4(1-18)$ & - \\
\hline Thrombolysis and aspirin & 12181 & 0.3 & 0.52 & $190(88-369)$ & _- \\
\hline Aspirin alone & 12181 & 0.29 & 0.024 & $85(33-148)$ & - \\
\hline ACE inhibitor & 12181 & 0.16 & 0.0065 & $13(5-30)$ & - \\
\hline$\beta$ Blocker & 12181 & 0.2 & 0.013 & $32(16-59)$ & - \\
\hline Secondary prevention post-MI & 36196 & - & 0.019 & $431(152-877)$ & $6 \%$ \\
\hline Aspirin alone & 36196 & 0.55 & 0.007 & $97(22-177)$ & - \\
\hline$\beta$ Blocker alone & 36196 & 0.15 & 0.023 & $94(23-55)$ & - \\
\hline Aspirin and $\beta$ blocker & 36196 & 0.05 & 0.029 & $39(42-218)$ & - \\
\hline ACE inhibitor & 36196 & 0.10 & 0.023 & $62(11-222)$ & - \\
\hline Simvastatin & 36196 & 0.10 & 0.006 & $17(2-59)$ & - \\
\hline Warfarin & 36196 & 0.05 & 0.010 & $15(3-50)$ & - \\
\hline Rehabilitation including exercise & 36196 & 0.19 & 0.020 & $117(43-258)$ & - \\
\hline Secondary prevention post-CABG/angioplasty & 11267 & 0.75 & 0.019 & $114(49-243)$ & $2 \%$ \\
\hline Angina & 156751 & - & 0.004 & $329(36-686)$ & $5 \%$ \\
\hline CABG surgery & 13384 & 1.00 & 0.010 & $131(95-387)$ & - \\
\hline Angioplasty & 6114 & 1.00 & 0.002 & $12(0-26)$ & - \\
\hline Unstable angina & 6450 & 1.00 & 0.005 & $34(4-90)$ & - \\
\hline Aspirin in community & 156751 & 0.33 & 0.004 & $152(32-570)$ & - \\
\hline Heart failure & 76978 & - & - & $563(489-617)$ & $8 \%$ \\
\hline Hospital & 9562 & 0.40 & 0.125 & $333(105-738)$ & - \\
\hline Community & 76978 & 0.20 & 0.030 & $362(38-1316)$ & _- \\
\hline Hypertension & 1935200 & 0.62 & 0.003 & $590(150-1132)$ & $9 \%$ \\
\hline Total treatments & & & & $2722(1373-5986)$ & $40 \%$ \\
\hline
\end{tabular}

* Minimum and maximum estimates.

MI, myocardial infarction; CPR, cardiopulmonary resuscitation.

\section{Myocardial infarction: initial treatment and} secondary prevention

In 1994, the combined effects of individual treatments for acute myocardial infarction prevented or postponed some 694 deaths (minimum estimate 366 , maximum estimate 1083 ) (table 1). Secondary prevention therapies after infarction, CABG surgery, and angioplasty together prevented a further 545 deaths.

Treatment of angina and heart failure

Angina therapies in hospital (unstable angina, CABG surgery, and angioplasty) and aspirin in the community together prevented an estimated 329 deaths (table 1). Heart failure treatment with ACE inhibitors in hospital and in the community together prevented an estimated 563 deaths.

Treatment of hypertension

Treatment for individual patients with hypertension prevented an estimated 590 deaths (table 1).
TOTAL TREATMENT MORTALITY REDUCTION In total, the medical and surgical treatments for acute myocardial infarction, secondary prevention, angina, heart failure, and hypertension together prevented or postponed an estimated 2722 deaths in 1994 (minimum estimate 1373, maximum 5986) (table 1).

\section{EFFECTS OF CHANGES IN POPULATION RISK} FACTORS

The best, maximum, and minimum estimates of CHD deaths prevented or postponed are detailed in table 2 .

\section{Smoking}

The mean population prevalence of smoking fell from $46 \%$ in 1975 to $28 \%$ in 1994 in men, and from $37 \%$ to $25 \%$ in women. This resulted in an estimated 2405 deaths prevented or postponed (minimum estimate 1792, maximum 3126) (table 2, appendix 2).

Table 2 Contribution of population risk factor changes to the fall in coronary heart disease mortality in Scotland, 1975 to 1994. Deaths prevented or postponed as a result of risk factor reductions

\begin{tabular}{|c|c|c|c|c|c|}
\hline Risk factor reduction & $\begin{array}{l}\text { Patients } \\
\text { eligible }\end{array}$ & $\begin{array}{l}\% \text { risk factor } \\
\text { reduction }\end{array}$ & $\begin{array}{l}\text { Absolute risk } \\
\text { reduction }\end{array}$ & $\begin{array}{l}\text { Total deaths prevented or } \\
\text { postponed }{ }^{\star}\end{array}$ & $\begin{array}{l}\text { Proportion of overall } \\
\text { deaths prevented or } \\
\text { postponed }\end{array}$ \\
\hline Smoking & 1935200 & 0.36 & 0.132 & $2405(1792-3126)$ & $36 \%$ \\
\hline Regression & & & 0.137 & $2492(2233-3126)$ & - \\
\hline Population attributable risk & & & 0.127 & $2318(1792-2846)$ & - \\
\hline Cholesterol & 1935200 & 0.05 & 0.021 & $383(71-1859)$ & $6 \%$ \\
\hline Regression & & & 0.037 & $669(501-1859)$ & - \\
\hline Population attributable risk & & & 0.005 & $97(71-1859)$ & - \\
\hline Population BP & 1935200 & 0.09 & 0.056 & $1015(319-2202)$ & $6 \% \dagger$ \\
\hline Regression & & & 0.090 & $1625(1263-2202)$ & - \\
\hline Population attributable risk & & & 0.022 & $404(319-842)$ & - \\
\hline Deprivation & 1935200 & 0.07 & 0.012 & $213(82-456)$ & $3 \%$ \\
\hline Population attributable risk & & & & & - \\
\hline Other factors & 1935200 & & 0.033 & $600(396-798)$ & $9 \%$ \\
\hline Total risk factors & & & & $4025(3417-4679)$ & $60 \%$ \\
\hline
\end{tabular}

${ }^{\star}$ Minimum and maximum estimates; $\uparrow 6 \%=15 \%$ for overall population blood pressure fall, minus $9 \%$ for hypertension treatment. 


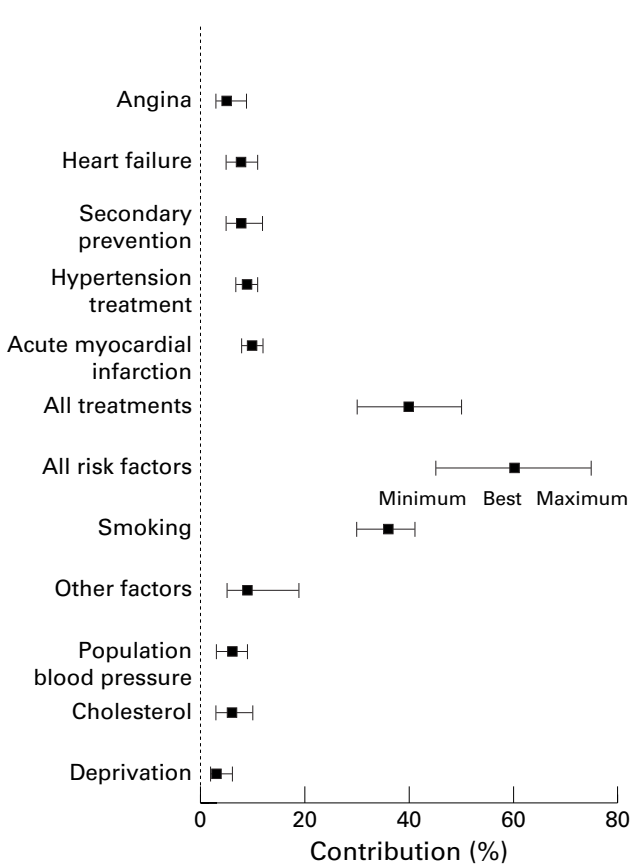

Figure 1 Sensitivity analysis: best, minimum, and maximum estimate of the contribution of specific treatments and risk factor changes to the coronary mortality fall in Scotland, 1975 to 1994.

\section{Cholesterol}

The $5 \%$ fall in population mean cholesterol concentration resulted in an estimated 383 deaths prevented or postponed (minimum 71, maximum 1859) (table 2).

\section{Population blood pressure}

The $9 \%$ fall in population mean diastolic blood pressure resulted in an estimated 1015 deaths prevented or postponed (minimum 319, maximum 2202) (table 2).

Change in socioeconomic status

The estimated small $(7 \%)$ increase in affluence in the overall Scottish population from 1975 to 1994 resulted in about 213 deaths prevented or postponed (minimum estimate 82 , maximum 456) (table 2).

TOTAL DEATHS PREVENTED OR POSTPONED BY ALL INTERVENTIONS AND RISK FACTOR CHANGES Combining the individual categories of patient groups, treatments, and averaging changes in specific risk factors suggested a shortfall in the model of approximately 600. As planned, this was pragmatically attributed to other, unquantified, factors. The combined estimated effects from all treatments and risk factor changes from 1975 to 1994 then totalled 6747 deaths prevented or postponed (minimum 4790, maximum 10695 (tables 1 and 2).

Comparison of observed and estimated mortality fall from 1975 to 1994

Treatments already in use in 1975 were estimated to have prevented or postponed approximately 544 deaths (minimum 234, maximum 1314). The estimated decline in deaths between 1975 and 1994 attributable to risk factor reductions and treatments over and above those provided in 1975 would therefore have been approximately 6203 (6747 minus 544). This was consistent with the observed fall of 6205 .

Of the estimated 6203 fewer deaths, 3558 $(57 \%)$ were in men. The benefit in men occurred particularly in younger age groups ( $25 \%$ in those aged $<65$ years, $17 \%$ in those aged $65-74$ years, and $15 \%$ in men aged $\geqslant 75$ years). In women, however, mortality benefit increased with age $(9 \%, 11 \%$, and $23 \%$, respectively). There was good agreement with the actual mortality falls between 1975 and 1994 observed in specific sex and age groups.

SENSITIVITY ANALYSIS

The proportional contribution of each treatment and risk factor change to the total mortality reduction of 6747 is illustrated in fig 1. Irrespective of whether one considered the best, maximum, or minimum mortality, these proportions remained relatively consistent.

Furthermore, the relative rankings remained the same for treatments: acute myocardial infarction first, then secondary prevention, heart failure, and angina; and for risk factor reductions, smoking first, then other factors, cholesterol, population blood pressure followed by deprivation (fig 1).

\section{Discussion}

This analysis suggests that modern therapies may account for about $40 \%$ of the decline in CHD mortality since 1975 . Half the reduction was apparently produced by falls in the four major risk factors: smoking, cholesterol, blood pressure, and deprivation. Although the estimation of each intervention was surrounded by uncertainty, their relative contributions remained remarkably consistent when subjected to a sensitivity analysis.

Relatively small scale interventions such as revascularisation by CABG surgery or angioplasty had a small population mortality effect. However, modest gains from other treatments applied to larger numbers produced a substantial cumulative survival benefit, ${ }^{24}{ }^{32}$ particularly acute myocardial infarction, secondary prevention, hypertension, and heart failure treatments. This also highlights the potential benefit which would arise from the more comprehensive application of effective treatments. ${ }^{11}$

Risk factor reductions accounted for a larger mortality benefit than treatments, as found in studies from the USA, Holland, Scandinavia, and New Zealand. ${ }^{1-4}{ }^{18-20} 29$ The reduction in smoking alone accounted for over one third of the total fall in Scottish coronary mortality. Most other studies also attributed $18-38 \%$ of their total mortality fall to smoking reduction, ${ }^{3418}$ although one, interestingly, only attributed $6 \% .{ }^{19}$ This then was a major prevention success, over 2400 fewer deaths. Yet almost $30 \%$ of adult Scots still smoke, resulting in at least 6000 preventable coronary deaths each year. ${ }^{14}$ Furthermore, cholesterol has hardly fallen in Scotland whereas other countries have benefited from more comprehensive and effective prevention programmes. ${ }^{3142030}$ 
Almost half the $15 \%$ mortality reduction associated with the fall in population blood pressure was attributable to secular trends, the remainder reflecting the treatment of hypertensive individuals. The mortality benefit attributable to increasing affluence was relatively modest, imprecise, and susceptible to confounding by smoking, diet, and blood pressure changes. Finally, the current model suggested that "other factors", presently unquantified, may account for about $10 \%$ of the mortality fall. Our initial focus on the four "major" risk factors was deliberate and pragmatic. ${ }^{3} 414$ 15 18-20 However, future studies will need to include potentially important factors such as obesity, exercise, diet, clotting factors, and cohort effects. ${ }^{14-16192029}$

There are limitations to any study of this type. $^{18-20}$ A robust sensitivity analysis was therefore necessary to test the key assumptions concerning population prevalence, treatment uptake, compliance, and absolute benefit. ${ }^{30}$ Future research might usefully compare the different CHD mortality models now available. $^{3}{ }^{18-20}$ The analysis assumed a minimal time lag between risk factor falls and mortality reductions; this was perhaps not unreasonable. . $^{3-14} 151930$

This study also focused entirely on mortality reduction, ignoring potential reductions in morbidity, hospital admissions, years of life lost, and quality of life. Symptom relief is a major benefit of modern therapies, including revascularisation, and should be explicitly considered in future work.

In conclusion, risk factor reductions and modern treatments contributed almost equally to the fall in coronary mortality in Scotland and, by implication, elsewhere in Britain. The more systematic application of proven medical therapies could produce large additional health gains. More active prevention strategies would substantially reduce deaths from CHD, as well as strokes and many cancers. Both are urgently required.

We thank many colleagues for very helpful discussions and comments, particularly Robert Beaglehole, Oliver Blatchford, Stuart Cobbe, Iain Crombie, George Davey-Smith, Andrew Davie, Iain Findlay, Ian Ford, Phil Hanlon, Ray Jones, Ross Lorimer, Jim McEwen, Phil McLoone, Sandy Muir, John Norrie, Jill Pell, Pekka Puska, Mary Seddon, Norman Sharpe, Susie Stewart, Hugh Tunstall-Pedoe, Andrew Walker, Harvey White, Robert Wilcox, Erkki Vartiainen, Charles Warlow, and David Wood. We are also very grateful to Ed Juszczak and James Boyd, Information and Statistics Division in Edinburgh, who provided additional linked patient data. Population and mortality data came by courtesy of the Registrar General for Scotland.

\section{Appendix 1 Epidemiological and audit studies used in this analysis}

a'Brooke R, Morrison CE, Tunstall-Pedoe H. The quality of epidemiological blood pressure measurements in the Glasgow MONICA risk factor surveys. $\mathcal{F}$ Epid Comm Health. [In press.]

Table AI Maximum and minimum estimates for deaths prevented or postponed

\begin{tabular}{llllc}
\hline & $\begin{array}{l}\text { Patient } \\
\text { numbers }(a)\end{array}$ & $\begin{array}{l}\text { Treatment } \\
\text { uptake }(b)\end{array}$ & $\begin{array}{l}\text { Absolute mortality } \\
\text { reduction }(c)\end{array}$ & $\begin{array}{l}\text { Deaths prevented or } \\
\text { postponed }(a \times b \times c)\end{array}$ \\
\hline Best estimate & 4482 & 0.3 & 0.052 & 69.9 \\
Minimum estimate & 4034 & 0.2 & 0.039 & 33.6 \\
Maximum estimate & 4930 & 0.4 & 0.065 & 128.2 \\
\hline
\end{tabular}

Kendrick S, Clarke J. The Scottish record linkage system. Health Bull 1993;51:72-9.

Capewell S, Gailey F, Fisher A, et al. A pilot audit of acute myocardial infarction management in south east Scotland. Health Bull 1997;55:399-407.

Capewell S, Kendrick S, Boyd J, et al. Measuring outcomes: one month survival after acute myocardial infarction in Scotland. Heart 1996;76:70-5.

Scottish Health Statistics 1996. Information and Statistics Division. Edinburgh, 1997.

McLoon P, Boddy FA. Deprivation and mortality in Scotland 1981-1991. BMF 1994;309:1465-70.

Clarke KW, Gray D, Hampton JR. Evidence of inadequate investigation and treatment of patients with heart failure. Br Heart $\mathcal{F}$ 1994;71:584-7.

Hillis GS, Trent RJ, Winton P, et al. Angiotensinconversing-enzyme inhibitors in the management of cardiac failure-are we ignoring the evidence? $\mathcal{f}$ Assoc Physicians 1996;89:145-50.

\section{Appendix 2 Two examples of mortality} reduction estimation used in this analysis EXAMPLE 1: MEN AGED 45-64 GIVEN THROMBOLYSIS PLUS ASPIRIN

In the second international study of infarct survival (ISIS 2), thrombolysis and aspirin reduced absolute mortality in men aged $45-64$ by 0.052 . Data from Glasgow MONICA ${ }^{12}$ and from Scottish surveys (Capewell 1996 and 1997, appendix 1) suggested that in Scotland in 1994, 4482 men aged 45-64 were admitted to hospital with an acute myocardial infarction, and that $30 \%$ were given thrombolysis and aspirin.

The deaths prevented or postponed for at least a year were therefore calculated as:

patient numbers $\times$ treatment uptake $\times$ absolute mortality reduction:

$=4482 \times 30 \% \times 0.052=70$ deaths prevented or postponed.

Some uncertainty obviously surrounded each of the estimates (patient numbers $( \pm 10 \%)$, treatment uptake $( \pm 50 \%$ ), compliance (not applicable in this case, but $\pm 30 \%$ elsewhere), and effectiveness $( \pm 25 \%)$ ).

An analysis of extremes was performed whereby the maximum and minimum feasible values were fed in to the model. By multiplying through, the resulting product then generated maximum and minimum estimates for deaths prevented or postponed (table AI).

This may be described as a "robust" approach for two reasons.

(1) Maximum and minimum values for each variable were deliberately forced to provide a wider range rather than a narrower one-for example, absolute mortality reduction $\pm 25 \%$ rather than, say, $\pm 15 \%$.

(2) The resulting product, for instance the minimum estimate, was generated by assuming that the lowest feasible values all occurred at the same time, a most unlikely situation.

EXAMPLE 2: MORTALITY FALL CAUSED BY REDUCTION IN SMOKING IN MEN AGED 45-64

In Scotland smoking prevalence in men aged 45-64 years fell from $50.5 \%$ to $31 \%$, an absolute reduction of $19.5 \%$, and a relative reduction of $39 \% .^{14}$

Pooling of studies from Finland, Iceland, and elsewhere $^{3429}$ produced a $\beta$ coefficient value of $0.43-$ that is, for every percentage point fall in relative smoking prevalence, the population CHD mortality would fall by $0.43 \%$.

The deaths prevented or postponed between 1975 and 1994 were then calculated as:

$\mathrm{CHD}$ deaths in that group in $1975 \times$ risk factor decline $\times \beta$ coefficient.

Thus $3615 \times 39 \% \times 0.43=606$ deaths prevented or postponed.

This calculation was then repeated: (a) for maximum and minimum values in that group; (b) for men and women in each age group; and (c) for each risk factor.

Additional details on the methodology are available from the authors. 
1 Beaglehole R. Medical management and the decline in mortality from coronary heart disease. BMF 1986;292:33-5. mortality rates: an analysis of the comparative effects of medical interventions and changes in lifestyle. Ann Intern Med 1984;101:825-36.

3 Vartiainen E, Puska P, Pekkanen J, et al. Changes in risk factors explain changes in mortality from ischaemic heart disease in Finland. BMF 1994;309:23-7.

4 Sigfusson N, Sigvaldason H, Steingrimsdottir L, et al Decline in ischaemic heart disease in Iceland and change in risk factor levels. BMF 1991;302:1371-5.

5 Collins R, Peto R, MacMahon S, et al. Blood pressure, stroke and coronary heart disease. Part 2, short term reductions in blood pressure: overview of randomised drug trials in their epidemiological context. Lancet 1990;335: 827-38.

6 Altman R, Carreras L, Diaz R, et al. Collaborative overview of randomised trials of antiplatelet therapy. 1: prevention of death, myocardial infarction, and stroke by prolonged death, myocardial infarction, and stroke by prolonged 1994;308:81-106.

7 Appleby P, Baigent C, Collins R, et al. Indications for fibrinolytic therapy in suspected acute myocardial infarction: collaborative overview of early mortality and major morbidity results from all randomised trials of more than 1000 patients. Lancet 1994;343:311-22.

8 Garg R, Yusuf S. Overview of randomized trials of angiotensin-converting enzyme inhibitors on mortality and morbidity in patients with heart failure. $7 A M A 1995 ; 273$ : 1450-6.

9 Latini R, Maggioni AP, Flather M, et al. Valvar inhibitor use in patients with myocardial infarction: summary of evidence from clinical trials. Circulation 1995;92:3132-7.

10 Pedersen TR. Randomised trial of cholesterol lowering in 4444 patients with coronary heart disease: the Scandinavian simvastatin survival study (4S). Lancet 1994;344: vian sim $1383-9$.

11 Bowker TJ, Clayton TC, Ingham J, et al. A British Cardiac Society survey of the potential for the secondary prevention Society survey of the potential for the secondary prevent
of coronary disease (ASPIRE). Heart 1996;75:334-42.

12 Tunstall Pedoe H, Morrison C, Woodward M, et al. Sex differences in myocardial infarction and coronary deaths in ferences in myocardial infarction and coronary deaths in the Scottish MONICA population of Glasgow 1985-1991: presentation, diagnosis, treatment and 28-day case fatality of 3991 events in men

3 Cobbe SM, Dalziel K, Ford I, et al. Survival of 1476 patients nitially resuscitated from out of hospital cardiac arrest. BMF 1996;312:633-7.

14 Coronary heart disease in Scotland. Report of a policy review Scottish Office Public Health Policy Unit. Edinburgh: HMSO, 1996.

15 Isles CG, Hole DJ, Hawthorne VM, et al. Relation between coronary risk and coronary mortality in women of the Renfrew and Paisley survey: comparison with men. Lancet 1992;339:702-6.

16 Smith WCS, Kenicer MB, Tunstall-Pedoe $\mathrm{H}$, et al. Prevalence of coronary heart disease in Scotland: Scottish heart health study. Br Heart f 1990;64:295-8.
17 McDonagh TA, Morrison CE, Tunstall-Pedoe $\mathrm{H}$, et al. Symptomatic and asymptomatic left ventricular systolic ysfunction in an urban population. Lancet 1997;350:82933

18 Bots ML, Grobee DE. Decline of coronary heart disease mortality in the Netherlands from 1978 to 1985: contribution of medical care and changes over time in presence of major cardiovascular risk factors. $\mathcal{F}$ Cardiovasc Risk 1996;3: 271-6.

19 Hunink MGM, Goldman L, Tosteson ANA, et al. The recent decline in mortality from coronary heart disease, 1980-1990: the effect of secular trends in risk factors and treatment. $\mathcal{F A M A} 1$ 1997; 277:535-42.

20 McGovern PG, Pankow JS, Shahar E, et al. Recent trends in acute coronary heart disease - mortality, morbidity, medical care, and risk factors. N Engl f Med 1996:334:884-90.

21 Tunstall Pedoe H, Bailey L, Chamberlain DA, et al. Survey of 3765 cardiopulmonary resuscitations in British hospitals (the BRESUS study): methods and overall results. BMf 1992;304:1347-51.

22 Lau J, Antman E M, Jiminez-Silva J, et al. Cumulative meta-analysis of therapeutic trials for myocardial infarction. N Engl f Med 1992;327:248-54.

23 Collins R, Baigent C, Peto R. Benefit of heparin plus aspirin versus aspirin alone in unstable angina. $\mathscr{F} A M A$ 1996;276: 1873-9.

24 Yusuf S, Zucker D, Peduzzi P, et al. Effect of coronary artery bypass graft surgery on survival: overview of 10 -year results from randomised trials by the coronary artery bypass graft surgery trialists collaboration. Lancet 1994;344:563-70.

25 Pocock SJ, Henderson RA, Rickards AF, et al. Meta analysis of randomized trials comparing coronary angioplasty with bypass-surgery. Lancet 1995;346:1184-9.

26 Smith WCS, Lee AJ, Crombie IK, et al. Control of blood pressure in Scotland: the rule of halves. BMF 1990;300: 981-3.

27 Mullen PD. Compliance becomes concordance. BMF 1997; 314:691-2.

28 Mant J, Hicks N. Detecting differences in quality of care: the sensitivity of measures of process and outcome in treating acute myocardial infarction. BMF 1995;311:793-6.

29 Dobson A, Filipiak B, Kuulasmaa K, et al. Relations of changes in coronary disease rates and changes in risk factor levels: methodological issues and a practical example. Am $\mathcal{f}$ Epidemiol 1996;143:1025-34.

30 Law MR, Wald NI, Thompson SG. By how much and how quickly does reduction in serum cholesterol concentration lower risk of ischaemic heart disease? BMF 1994;308:36773 .

31 Briggs A, Sculpher M, Buxton M. Uncertainty in the economic evaluation of health care technologies: the role of sensitivity analysis. Health Economics 1994;3:95-104.

32 Doliszny KM, Luepker RV, Burke GL, et al. Estimated contribution of coronary artery bypass graft surgery to the decline in coronary heart disease mortality - the Minnesota heart study. F Am Coll Cardiol 1994;24:95-103. 